\title{
IMPACT AESTHETICS: \\ BACK TO THE FUTURE IN DIGITAL CINEMA?
}

\section{Scott McQuire}

\section{Millennial fantasies}

As anyone interested in film culture knows, the last decade has witnessed an explosion of pronouncements concerning the future of cinema. Many are fuelled by naked technological determinism, resulting in apocalyptic scenarios in which cinema either undergoes digital rebirth to emerge more powerful than ever in the new millennium, or is marginalised by a range of 'new media' which inevitably include some kind of broadband digital pipe capable of delivering full screen 'cinema quality' pictures on demand to home consumers. The fact that the doubleedged possibility of digital renaissance or death by bytes has coincided with celebrations of the 'centenary of cinema' has undoubtedly accentuated desire to reflect more broadly on the history of cinema as a social and cultural institution. It has also intersected with a significant transformation of film history, in which the centrality of 'narrative' as the primary category for uniting accounts of the technological, the economic and the aesthetic in film theory, has become subject to new questions. Writing in 1986 Thomas Elsaesser joined the revisionist project concerning 'early cinema' to cinema's potential demise: 'A new interest in its beginnings is justified by the very fact that we might be witnessing the end: movies on the big screen could soon be the exception rather than the rule'. ${ }^{1}$

Of course, Elsaesser's speculation, which was largely driven by the deregulation of television broadcasting in Europe in conjunction with the emergence of new technologies such as video, cable and satellite in the 1980s, has been contradicted by the decade long cinema boom in the multiplexed 1990s. ${ }^{2}$ It has also been challenged from another direction, as the giant screen 'experience' of large format cinema has been rather unexpectedly transformed from a bit player into a prospective force. However, in the same article, Elsaesser raised another issue which has continued to resonate in subsequent debates: 
Few histories fully address the question of why narrative became the driving force of cinema and whether this may itself be subject to change. Today the success, of SF as a genre, or of directors like Steven Spielberg whose narratives are simply anthology pieces from basic movie plots, suggest that narrative has to some extent been an excuse for the pyrotechnics of IL\&M. ${ }^{3}$

Concern for the demise, if not of cinema per se, then of narrative in cinema, is widespread in the present. In the recent special 'digital technology' issue of Screen, Sean Cubitt noted a 'common intuition among reviewers, critics and scholars that something has changed in the nature of cinema - something to do with the decay of familiar narrative and performance values in favour of the qualities of the blockbuster'. ${ }^{4}$ Lev Manovich has aligned the predominance of 'blockbusters' with 'digital cinema' by defining the latter almost entirely in terms of increased visual special effects: 'A visible sign of this shift is the new role which computer generated special effects have come to play in the Hollywood industry in the last few years. Many recent blockbusters have been driven by special effects; feeding on their popularity'. ${ }^{5}$ In his analysis of Hollywood's often anxious depiction of cyberspace in films such as The Lawn Mower Man (1992), Paul Young argues that 'cyberphobic films overstress the power of the visual in their reliance on digital technology to produce spectacle at the expense of narrative', and adds this is 'a consequence that [Scott] Bukatman has argued is latent in all special effects' ${ }^{6}$ A more extreme (but nevertheless common) view is expressed by film maker Jean Douchet: '[Today] cinema has given up the purpose and the thinking behind individual shots [and narrative], in favour of images - rootless, textureless images - designed to violently impress by constantly inflating their spectacular qualities'. ${ }^{7}$

'Spectacle', it seems, is winning the war against 'narrative' all along the line. Even a brief statistical analysis reveals that 'special effects' driven films have enjoyed enormous recent success, garnering an average of over $60 \%$ of the global revenue taken by the top 10 films from 1995-1998, compared to an average of $30 \%$ over the previous four years. ${ }^{8}$ Given that the proportion of box office revenue taken by the top 10 films has held steady or increased slightly in the context of a rapidly expanding total market, this indicates that a handful of special-effects films are generating huge revenues each year. While such figures don't offer a total picture of the film industry, let alone reveal which films which will exert lasting cultural influence, they do offer a snapshot of contemporary cultural taste refracted through studio marketing budgets. Coupled to the recent popularity of paracinematic forms, such as large format and special venue films, the renewed emphasis on 'spectacle' over 'narrative' suggests another possible end-game for 
cinema: not the frequently prophesied emptying of theatres made redundant by the explosion of home-based viewing (television, video, the internet), but a transformation from within which produces a cinema no longer resembling its (narrative) self, but something quite other.

Complementing these debates over possible cinematic futures is the fact that any turn to spectacular film 'rides' can also be conceived as a return - whether renaissance or regression is less clear - to an earlier paradigm of film-making famously dubbed the 'cinema of attraction' by Tom Gunning. Gunning long ago signalled this sense of return when he commented: 'Clearly in some sense recent spectacle cinema has re-affirmed its roots in stimulus and carnival rides, in what might be called the Spielberg-Lucas-Coppola cinema of effects'. ${ }^{9}$ For Paul Arthur, developments in the 1990s underline the point:

The advent of Imax 3-D and its future prospects, in tandem with the broader strains of a New Sensationalism, provide an occasion to draw some connections with the early history of cinema and the recurrent dialectic between the primacy of the visual and, for lack of a better term, the sensory. ${ }^{10}$

In what follows here, I want to further consider the loops and twists of these debates, not so much with the grand ambition of resolving them, but firstly of adding some different voices to the discussion - particularly the voices of those involved in film production. ${ }^{11}$ My intention is not to elevate empiricism over theory, but to promote dialogue between different domains of film culture which meet all too rarely, and, in the process, to question the rather narrow terms in which 'digital cinema' has frequently entered recent theoretical debates. Secondly, I want to consider the relation between 'narrative' and 'spectacle' as it is manifested in these debates. My concern is that there seems to be a danger of confusing a number of different trajectories - such as cinema's on-going efforts to demarcate its 'experience' from that of domestic entertainment technologies, and the turn to blockbuster exploitation strategies - and conflating them under the heading of 'digital cinema'. While digital technology certainly intersects with, and significantly overlaps these developments, it is by no means co-extensive with them.

\section{'Spectacular sounds': cinema in the digital domain}

Putting aside the inevitable hype about the metamorphosis of Hollywood into 'Cyberwood', like many others I am convinced that digital technology constitutes a profound revolution in cinema, primarily because of its capacity to cut across all 
sectors of the industry simultaneously, affecting film production, narrative conventions and audience experience. In this respect, the only adequate point of reference for the depth and extent of current changes are the transformations which took place with the introduction of synchronised sound in the 1920s.

However, while the fundamental level at which change is occurring is widely recognised, it has been discussed primarily in terms of the impact of CGI (computer-generated imaging) on the film image. A more production-oriented approach would most likely begin elsewhere; with what Philip Brophy has argued is among 'the most overlooked aspects of film theory and criticism (both modern and postmodern strands)' - sound. ${ }^{12}$ A brief flick through recent articles on digital cinema confirms this neglect: Manovich locates 'digital cinema' solely in a historical lineage of moving pictures; none of the articles in the recent Screen dossier mention sound, and even Eric Faden's 'Assimilating New Technologies: Early Cinema, Sound and Computer Imaging' only uses the introduction of synchronised sound as an historical analogy for discussing the contemporary effect of CGI on the film image ${ }^{13}$.

While not entirely unexpected, this silence is still somewhat surprising, given the fact that digital sound technology was adopted by the film industry far earlier and more comprehensively than was CGI. And, at least until the early 1990s with films like Terminator 2 (1991) and Jurassic Park (1993), the effect on audience experience was arguably far greater than was digital imaging. Dominic Case [Group Services and Technology Manager at leading Australian film processor Atlab] argued in 1997:

I am more and more convinced that the big story about film technology as far as audiences are concerned in the past few years has been sound. Because, although you can do fancy digital things, the image remains glued to that bit of screen in front of your eyes, and it's not really any bigger... But the sound has gone from one woolly sound coming from the back of the screen with virtually no frequency range or dynamic range whatsoever ... to something that fills the theatre in every direction with infinitely more dynamic range and frequency range. To me, that's an explosion in experience compared to what you are seeing on the screen.

However, the visual bias of most film theory is so pervasive that this transformation often passes unremarked. Part of the problem is that we lack the necessary conceptual armature: there are no linkages which pull terms such as 
'aural' or 'listener' into the sort of semantic chain joining spectacle and spectator to the adjective 'spectacular'. Film sound-mixer Ian McLoughlin notes:

Generally speaking, most people are visually trained from birth. ... Very few people are trained to have a aural language and, as a result there isn't much discussion about the philosophy of the sound track. ... There has been very, very little research done into the psycho-acoustic effects of sound and the way sound works sociologically on the audience. ${ }^{14}$

Compounding this absence is the fact that the digital revolution in sound is, in many respects, the practical realisation of changes initiated with the introduction of Dolby Stereo in 1975. (On the other hand, the fact that CGI entered a special effects terrain already substantially altered by techniques of motion control, robotics and animatronics didn't prevent critical attention to it.) Four-track Dolby stereo led to a new era of sound experimentation beginning with films such as Star Wars (1977) and Close Encounters of the Third Kind (1977). As renowned sound mixer Roger Savage (whose credits include Return of the Jedi, 1983; Shine, 1996; and Romeo + Juliet, 1996) recalls: 'Prior to that, film sound hadn't changed for probably 30 years. It was Mono Academy ... Star Wars was one of the first films that I can remember where people started coming out of the theatre talking about the sound track'.15

While narrative sound effects such as dialogue and music were still generally concentrated in the front speakers, the surround sound speakers became the vehicles for a new range of 'spectacular' sound effects. In particular, greater emphasis was given to boosting low frequency response, explicitly mirroring the amplified ambience of rock music. There was also greater attention given to the 'spatialisation' of discrete sound elements within the theatre. As Rich Altman has argued, these developments presented a significant challenge to one of the fundamental precepts of classical Hollywood narrative: the unity of sound and image and the subservience of sound effects to narrative logic:

Whereas Thirties film practice fostered unconscious visual and psychological spectator identification with characters who appear as a perfect amalgam of image and sound, the Eighties ushered in a new kind of visceral identification, dependent on the sound system's overt ability, through bone-rattling bass and unexpected surround effects, to cause spectators to vibrate - quite literally - with the entire narrative space. It is thus no longer the eyes, the ears and the brain that alone initiate identification and maintain contact with a sonic 
source; instead, it is the whole body that establishes a relationship, marching to the beat of a different woofer. Where sound was once hidden behind the image in order to allow more complete identification with the image, now the sound source is flaunted, fostering a separate sonic identification contesting the limited rational draw of the image and its characters. ${ }^{16}$

Altman's observation is significant in this context, inasmuch as it suggests that the dethroning of a certain model of narrative cinema had begun prior to the digital threshold, and well before the widespread use of CGI. It also indicates the frontline role that sound took in the film industry's initial response to the incursions of video : in the 1980s the new sound of cinema was a primary point of differentiation from domestic image technologies.

However, while Dolby certainly created a new potential for dramatic sound effects, in practice most film makers remained limited by a combination of logistical and economic constraints. In this respect, the transition to digital sound has been critical in creating greater latitude for experimentation within existing budget parameters and production time frames. In terms of sound production, Roger Savage argues: 'The main advantages in digital are the quality control, the speed and the flexibility'. (This is a theme which is repeated with regard to the computerisation of other areas of film making such as picture editing and CGI.) Enhanced speed, flexibility and control stem from a reduction in the need for physical handling and a refinement of precision in locating and manipulating individual elements. In sound production, libraries of analogue tape reels each holding ten minutes of sound have given way to far more compact DAT tapes and hard drive storage. The entire production process can now often be realised on a single digital workstation. There is no need for a separate transfer bay, and, since digital processing involves the manipulation of electronic data, there is no risk of degrading or destroying original recordings by repeated processing. Once the sounds are catalogued, digital workstations grant random access in a fraction of a second (eliminating tape winding time), and, unlike sprocket-based sound editing, all the tracks which have been laid can be heard immediately in playback.

The creative pay-off is an enhanced ability to add complexity and texture to soundtracks. In terms of sound reproduction, the most marked change resulting from six track digital theatre systems is improved stereo separation and frequency response which assists better music reproduction in theatres - a change which goes hand in glove with the increased prominence that music and soundtracks have assumed in promoting and marketing films in recent years. 
The enhanced role of sound in cinema is even more marked for large format films which, because of their high level of visual detail, demand a correspondingly high level of audio detail. Ian McLoughlin (who, amongst many other things, shares sound mixing credits with Savage for the large-format films Africa's Elephant Kingdom, 1998 and The Story of a Sydney, 1999) comments:

If you look at the two extremes of image technology, if you look at television, and then you look at something like Imax, the most interesting difference is the density of the sound track that is required with the size of the picture. When you're doing a TV mix, you try to be simple, bold. You can't get much in or otherwise it just becomes a mess. With $35 \mathrm{~mm}$ feature films you're putting in 10, 20 times more density and depth into the sound track as compared to television, and ... when you go to Imax, you need even more.

McLoughlin also makes a significant point concerning the use (or abuse) of digital sound:

When digital first came out and people found that they could make a enormously loud sound tracks, everyone wanted enormously large sound tracks.... Unfortunately some people who present films decided that the alignment techniques that companies like Dolby and THX have worked out aren't to their liking and they think audiences like a lot of sub-base and so they sometimes wind that up.... [S]uddenly you've got audiences with chest cavities being punched due to the amount of bottom end. ... Dolby and screen producers and screen distributors in America have actually been doing a lot of research into what they are calling the 'annoyance factor' of loud sound tracks. Because audiences are getting turned off by overly jarring, overly sharp, sound tracks.

This comment is worth keeping in mind for two reasons. Firstly, it underlines the fact that the image is by no means the only vehicle for producing cinematic affect: in this sense, 'impact aesthetics' offers a more apt description of the trajectory of contemporary cinema than 'spectacle'. Secondly, it warns against making hasty generalisations when assessing the long-term implications of CGI. While digital imaging undoubtedly represents a significant paradigm shift in cinema, it is also feasible that the 1990s will eventually be seen more as a teething period of 'gee whizz' experimentation with the new digital toolbox, which was gradually turned towards other (even more 'narrative') ends. (The way we now look at early sound films is instructive: while contemporary audiences were fascinated by the mere 
fact that pictures could 'talk', in retrospect we tend to give more weight to the way sound imposed new restrictions on camera movement, location shooting and acting style).

\section{Painting with light}

In contrast to the relative dearth of attention given to changes in areas such as sound and picture editing, digital manipulation of the film image has received massive publicity. While this is partly the result of deliberate studio promotion, it also reflects the profound changes in cinematic experience that computers have set in train. When we can see Sam Neil running from a herd of dinosaurs - in other words, when we see cinematic images offering realistic depictions of things we know don't exist - it is evident that the whole notion of photo-realism which has long been a central plank of cinematic credibility is changing.

But how should this change be understood? Is it simply that 'live action' footage can now be 'supplemented' with CG elements which replace earlier illusionistic techniques such as optical printing, but leave cinema's unique identity as an 'art of recording' intact? Or is a new paradigm emerging in which cinema becomes more like painting or animation? Lev Manovich has recently taken the latter position to an extreme, arguing that, 'Digital cinema is a particular case of animation which uses live-action footage as one of its many elements', and concluding: 'In retrospect, we can see that twentieth century cinema's regime of visual realism, the result of automatically recording visual reality, was only an exception, an isolated accident in the history of visual representation...'.17

While I suspect that Manovich significantly underestimates the peculiar attractions of 'automatic recording' (which produced what Walter Benjamin termed the photograph's irreducible 'spark of contingency', what Barthes ontologised as the photographic punctum), it is clear the referential bond linking camera image to physical object has come under potentially terminal pressure in the digital era. However, any consideration of 'realism' in cinema is immediately complicated by the primacy of fictional narrative as the dominant form of film production and consumption. Moreover, cinema swiftly moved from adherence to the ideal of direct correspondence between image and object which lay at the heart of classical claims to photographic referentiality. 'Cheating' with the order of events, or the times, locations and settings in which they occur, is second nature to film-makers. By the time cinema 'came of age' in the picture palace of the 1920s, a new logic of montage, shot matching and continuity had coalesced into the paradigm of 
'classical narrative', and cinematic credibility belonged more to the movement of the text rather than the photographic moment - a shift Jean-Louis Commolli has neatly described in terms of a journey from purely optical to psychological realism. ${ }^{18}$

Within this paradigm all imaginable tactics were permissible in order to imbue pro-filmic action with the stamp of cinematic authority - theatrical techniques such as performance, make-up, costumes, lighting and set design were augmented by specifically cinematic techniques such as stop motion photography and rear projection, as well as model-making and matte painting which entered the screen world via the optical printer. Given this long history of simulation, the digital threshold is perhaps best located in terms of its effect on what Stephen Prince has dubbed 'perceptual realism', rather than in relation to an abstract category of 'realism' in general. Prince argues:

A perceptually realistic image is one which structurally corresponds to the viewer's audio-visual experience of three-dimensional space ... Such images display a nested hierarchy of cues which organise the display of light, colour, texture, movement and sound in ways that correspond to the viewer's own understanding of these phenomena in daily life. Perceptual realism, therefore, designates a relationship between the image on film and the spectator, and it can encompass both unreal images and those which are referentially realistic. Because of this, unreal images may be referentially fictional but perceptually realistic. ${ }^{19}$

I have emphasised Prince's evocation of fidelity to 'audio-visual experience' because it underlines the extent to which the aim of most computer artists working in contemporary cinema is not simply to create high resolution images, but to make these images look as if they might have been filmed. This includes adding various 'defects', such as film grain, lens flare, motion blur and edge halation. CG effects guru Scott Billups argues that film makers had to 'educate' computer programmers to achieve this end:

For years we were saying: 'Guys, you look out on the horizon and things get grayer and less crisp as they get farther away'. But those were the types of naturally occurring event structures that never got written into computer programs. They'd say ‘Why do you want to reduce the resolution? Why do you want to blur it?'.20 
By the 1990s many software programs had addressed this issue. As Peter Webb (one of the developers of Flame) notes:

Flame has a lot of tools that introduce the flaws that one is trained to see.

Even though we don't notice them, there is lens flare and motion blur, and the depth of field things, and, if you don't see them, you begin to get suspicious about a shot. ${ }^{21}$

In other words, because of the extent to which audiences have internalised the camera's qualities as the hallmark of credibility, contemporary cinema no longer aims to mime 'reality', but 'camera-reality'. Recognising this shift underlines the heightened ambivalence of realism in the digital domain. The film maker's ability to take the image apart at ever more minute levels is counterpointed by the spectator's desire to comprehend the resulting image as 'realistic' - or, at least, equivalent to other cine-images. In some respects, this can be compared to the dialectic underlying the development of montage earlier this century, as a more 'abstract' relation to individual shots became the basis for their reconstitution as an 'organic' text. But instead of the fragmentation and re-assemblage of the image track over time, which founded the development of classical narrative cinema and its core 'grammatical' structures such as shot/reverse shot editing, digital technology introduces a new type of montage: montage within the frame whose prototype is the real time mutation of morphing.

However, while 'perceptual realism' was achieved relatively painlessly in digital sound, the digital image proved far more laborious. Even limited attempts to marry live action with CGI, such as TRON (1982) and The Last Starfighter (1984) proved unable to sustain the first wave of enthusiasm for the computer. As one analyst observed: 'The problem was that digital technology was both comparatively slow and prohibitively expensive. In fact, workstations capable of performing at film resolution were driven by Cray super-computers' ${ }^{22}$ It is these practical exigencies, coupled to the aesthetic disjunction separating software programmers from film makers I noted above, rather than a deeply felt desire to manufacture a specifically electronic aesthetic, which seems to underlie the 'look' of early CGI. ${ }^{23}$

Exponential increases in computing speed, coupled to decreases in computing cost, not only launched the desktop PC revolution in the mid-1980s, but made CGI in film an entirely different matter. The second wave of CGI was signalled when Terminator 2: Judgement Day (1991) made morphing a household word. ${ }^{24}$ Two 
years later the runaway box-office success of Jurassic Park (1993) changed the question from whether computers could be effectively used in film making to how soon this would happen. The subsequent rash of CGI-driven blockbusters, topped by the billion dollar plus gross of Cameron's Titanic (1997), has confirmed the trajectory.

Cameron is one of many influential players who argue that cinema is currently undergoing a fundamental transformation: 'We're on the threshold of a moment in cinematic history that is unparalleled. Anything you imagine can be done. If you can draw it, if you can describe it, we can do it. It's just a matter of cost'..$^{25}$ While this claim is true at one level - many tricky tasks such as depicting skin, hair and water, or integrating CGI elements into live action images shot with a hand-held camera, have now been accomplished successfully - it is worth remembering that 'realism' is a notoriously slippery goal, whether achieved via crayon, camera or computer. Dennis Muren's comments on his path-breaking effects for Jurassic Park (which in fact had only 5 to 6 minutes of CGI and relied heavily on models and miniatures, as did more recent 'state of the art' blockbusters such as The Fifth Element, 1997 and Dark City, 1998) bear repeating: 'Maybe we'll look back in 10 years and notice that we left things out that we didn't know needed to be there until we developed the next version of this technology'. Muren adds:

In the Star Wars films you saw lots of X-wings fighters blow up, but these were always little models shot with high-speed cameras. You've never seen a real X-wing blow up, but by using CGI, you might just suddenly see what looks like a full-sized X-wing explode. It would be all fake of course, but you'd see the structure inside tearing apart, the physics of this piece blowing off that piece. Then you might look back at Star Wars and say, 'That looks terrible'..$^{26}$

Clearly, George Lucas shared this sentiment, acknowledging in 1997 that 'I'm still bugged by things I couldn't do or couldn't get right, and now I can fix them' ${ }^{27}$ The massive returns generated by the 'digitally enhanced' Star Wars trilogy raises the prospect of a future in which blockbuster movies are not re-made with new casts, but perpetually updated with new generations of special effects.

\section{Stop the sun, I want to get off}

Putting aside the still looming question of digital projection, the bottom line in the contemporary use of digital technology in cinema is undoubtedly 'control': 
particularly the increased control that film makers have over all the different components of image and sound tracks. Depending on a film's budget, the story no longer has to work around scenes which might be hard to set up physically or reproduce photo-optically - they are all grist to the legions of screen jockeys working in digital post-production houses. George Lucas extols the new technology for enhancing the ability to realise directorial vision:

I think cinematographers would love to have ultimate control over the lighting; they'd like to be able to say, 'OK, I want the sun to stop there on the horizon and stay there for about six hours, and I want all of those clouds to go away. Everybody wants that kind of control over the image and the storytelling process. Digital technology is just the ultimate version of that. ${ }^{28}$

A direct result of digital imaging and compositing techniques has been an explosion of films which, instead of 'fudging' the impossible, revel in the capacity to depict it with gripping 'realism': Tom Cruise's face can be ripped apart in real time (Interview with the Vampire, 1994), the Whitehouse can be incinerated by a fireball from above (Independence Day, 1996), New York can be drowned by a tidal wave, or smashed by a giant lizard(Deep Impact, Godzilla, 1998).

But, despite Lucas' enthusiasm, many are dubious about where the new primacy of special effects leaves narrative in cinema. The argument put forward by those such as Sean Cubitt and Scott Bukatman is that contemporary special effects tend to displace narrative insofar as they introduce a disjunctive temporality evocative of the sublime. Focusing on Doug Trumbull's work, Bukatman emphasises the contemplative relationship established between spectator and screen in key effects scenes (a relationship frequently mirrored by on-screen characters displaying their awe at what they- and 'we' - are seeing. $)^{29}$ Cubitt suggests that similar 'fetishistic' moments occur in songs such as Diamonds are a Girl's Best Friend, where narrative progress gives way to visual fascination. His example is drawn from a strikingly similar terrain to that which inspired Laura Mulvey's well-known thesis on the tension between voyeurism and scopophilia in classical narrative cinema:

Mainstream film neatly combined spectacle and narrative. (Note, however, in the musical song-and-dance numbers break the flow of the diegesis). The presence of woman is an indispensable element of spectacle in normal narrative film, yet her visual presence tends to work against the development of a story line, to freeze the flow of action in moments of erotic contemplation. ${ }^{30}$ 
This connection was also made by Tom Gunning in his work on the early 'cinema of attraction': 'As Laura Mulvey has shown in a very different context, the dialectic between spectacle and narrative has fueled much of the classical cinema'. ${ }^{31}$

In this respect, a key point to draw from both Mulvey and Gunning is to recognise that they don't conceive the relationship between spectacle and narrative in terms of opposition but dialectical tension. ${ }^{32}$ This is something that other writers have sometimes forgotten. Presenting the issue in terms of an opposition (spectacle versus narrative) in fact recycles positions which have been consistently articulated (and regularly reversed) throughout the century. In the 1920s, avant-garde film makers railed against 'narrative' because it was associated primarily with literary and theatrical scenarios at the expense of cinematic qualities (Gunning begins his 'Cinema of Attraction' essay with just such a quote from Fernand Léger). Similar concerns emerged with debates in France over auteur theory in the 1950s, where the literary qualities of script were opposed to the 'properly cinematic' qualities of mise-en-scene. In the 1970s, the 'refusal of narrative' which characterised much Screen theory of the period, took on radical political connotations. Perhaps as a reaction to the extremity of pronouncements by those such as Peter Gidal, there has been a widespread restoration of narrative qualities as a filmic 'good object' in the present. However, rather than attempting to resolve this split in favour of one side or the other, the more salient need is to examine their irreducible intertwining: what sort of stories are being told, and what sort of spectacles are being deployed in their telling?

While it is easy to lament the quality of story-telling in contemporary blockbusters, few critics seriously maintain that such films are without narrative. A more productive framework is to analyse why explicitly 'mythological' films such as the Star Wars cycle have been able to grip popular imagination at this particular historical conjuncture, marrying the bare bones of fairy-tale narrative structures to the inculcation of a specific type of special effects driven viewing experience. (To some extent, ths is Bukatman's approach in his analysis of special effects). In this context, it is also worth remembering that, despite the quite profound transformations set in train by the use of digital technology in film making, there has thus far been little discernible effect on narrative in terms of structure or genre. The flirtation with 'non-linear' and 'interactive' films was a shooting star which came and went with the CD-ROM, while most contemporary blockbusters conform smoothly to established cine-genres (sci-fi, horror, disaster and action- 
adventure predominating), with a significant number being direct re-makes of older films done 'better' in the digital domain.

One of the more interesting observations about possible trends in the industry is put forward by James Cameron, who has argued that digital technology has the potential to free film makers from the constraints of the ' $\mathrm{A}$ ' and ' $\mathrm{B}$ ' picture hierarchy:

[I]n the '40s you either had a movie star or you had a B-movie. Now you can create an A-level movie with some kind of visual spectacle, where you cast good actors, but you don't need an Arnold or a Sly or a Bruce or a Kevin to make it a viable film. ${ }^{33}$

However, Cameron himself throws doubt on the extent of this 'liberation' by underlining the industrial nature of digital film production. ${ }^{34}$ In practice, any film with the budget to produce a large number of cutting edge special effects shots is inevitably sold around star participation, as well as spectacle (as were films such as The Robe, 1953 and Ben Hur, 1926).

This point about the intertwining of narrative and spectacle is re-inforced if we look at developments in large-format film, an area frequently singled out for its over-dependence on screen spectacle to compensate for notoriously boring 'educational' narrative formats. Large-format (LF) cinema is currently in the throes of a significant transformation The number of screens worldwide has exploded in the last four years (between 1995 and January 1999, the global LF circuit grew from 165 to 263 theatres. By January 2001, another 101 theatres are due to open, taking the total to 364, an increase of $120 \%$ in 6 years). More significantly, the majority of new screens are being run by commercial operators rather than institutions such as science museums. These new exhibition opportunities, coupled to the box-office returns generated by films such as Everest (the 15th highest grossing film in the USA in 1998, despite appearing on only 32 screens) has created significant momentum in the sector for the production of LF films capable of attracting broader audiences. For some producers, this means attempting to transfer the narrative devices of dramatic feature films onto the giant screen, while others argue that the peculiarities of the medium means that LF needs to stick with its proven documentary subjects.

However, most significantly in this context, none dispute the need for the sector to develop better narrative techniques if it is to grow and prosper, particularly by 
attracting 'repeat' audiences. In many respects, the LF sector is currently in a similar position to cinema in the 1900s, with people going to see the apparatus rather than a specific film, and the 'experience' being advertised largely on this basis. While it would be simplistic to see current attempts to improve the narrative credentials of LF films as a faithful repetition of the path that $35 \mathrm{~mm}$ cinema took earlier this century, since most production is likely to remain documentary-oriented, it would be equally as foolish to ignore the cultural and commercial imperatives which still converge around telling a 'good story' ${ }^{35}$

\section{Distraction and the politics of spectacle}

Despite the current rash of digitally-inspired predictions, narrative in film is unlikely to succumb to technological obsolescence. But nor will spectacle be vanquished by a miraculous resurgence of 'quality' stories. A corollary of a dialectical conception of the interrelationship between narrative and spectacle is that neither should be seen simply as 'good' or 'bad' objects in themselves. For Mulvey, spectacle (exemplified by close-ups which turn woman's face and body into a fetish), as well as the more voyeuristic strategy of narrative, were both attuned to the anxious imagination of patriarchal culture in classical cinema. Both were techniques for negotiating the threat of castration raised by the image of woman, an image classical cinema simultaneously desired and sought to circumscribe or punish. Nevertheless, even within this heavily constrained context, 'spectacle' could also assume a radical function by 'interrupting' the smooth functioning of narrative, disturbing the rules of identification and the systematic organisation of the look within the text. (This is the gist of her comparison between the films of von Sternberg, which privilege a fetish image of Dietrich over narrative progress, and those of Hitchcock which more closely align the viewer with the male protagonist).

Can spectacle still exert a 'progressive' function in contemporary cinema? While most critics answer this question negatively without even posing it, Paul Young is unusual in granting a measure of radical effect to the renewed primacy of spectacle. Young draws on Miriam Hansen's account of the 'productive ambiguity' of early cinema, in which the lack of standardised modes of exhibition, coupled to reliance on individual attractions, gave audiences a relative freedom to interpret what they saw, and established cinema as (potentially) an alternative public sphere. He takes this as support for his argument that contemporary 'spectacle' cinema constitutes an emergent challenge to 'Hollywood's institutional identity'. ${ }^{36}$ 
Young's analysis contrasts markedly with Gunning's earlier description of the 'cinema of effects' as 'tamed attractions'. ${ }^{37}$ Nevertheless both share some common ground: Young's reference to the 'productive ambiguity' of early cinema, like Gunning's rather oblique and undeveloped reference to the 'primal power' of attraction, draws nourishment from Siegfried Kracauer's early writings on the concept of distraction. In the 1920s, Kracauer set up 'distraction' as a counterpoint to contemplation as a privileged mode of audience reception, seeing it as embodying a challenge to bourgeois taste for literary-theatrical narrative forms, and also as the most compelling mode of presentation to the cinema audience of their own disjointed and fragmented conditions of existence. ${ }^{38}$ While distraction persisted as a category used by Walter Benjamin in his 'Artwork' essay of the mid1930s, by the 1940s Kracauer seemed to have revised his position. As Elsaesser has pointed out, this re-appraisal was at least partly a re-assessment of the 'productive ambiguity' which had characterised social spaces such as cinema; by the 1940s distraction and spectacle had been consolidated into socially dominant forms epitomised by Hollywood on the one hand and fascism on the other. ${ }^{39}$

If Kracauer's faith that the 1920s audience could symptomatically encounter 'its own reality' via the superficial glamour of movie stars rather than the putative substance of the era's 'high culture' was already shaken by the 1940s, what would he make of the post-pop art, postmodern 1990s? The extent to which surface elements of popular culture have been aesthetically 'legitimated' without any significant transformation of corresponding political and economic values suggests the enormous difficulties facing those trying to utilise spectacle as a 'progressive' element in contemporary culture. However, it is equally important to acknowledge that this problem cannot be resolved simply by appealing to 'narrative' as an antidote. While the terms remain so monolithic, the debate will not progress beyond generalities.

In this respect, Kracauer's work still offers some important lessons to consider in the present. Here, by way of conclusion, I want to sketch out a few possible lines of inquiry. On the one hand, his concept of the 'mass ornament' indicates that any turn, or return, to spectacle in cinema needs to be situated in a wider social context. ${ }^{40}$ Spectacle is not simply a matter of screen image, but constitutes a social relation indexed by the screen (something Guy Debord underlined in the 1960s). Developments in contemporary cinema need to be related to a number of other trajectories, including cinema's on-going endeavours to distinguish its 'experience' 
from that of home entertainment, as well as the proliferation of spectacle in social arenas as diverse as sport (the Olympic games), politics (the dominance of the cult of personality in all political systems) and war (the proto-typical 'media-event').

On the other hand, the specific forms of spectacle mobilised in contemporary cinema need to be examined for the extent to which they might reveal (in Kracauer's terms) the 'underlying meaning of existing conditions'. Kracauer's analysis of cinema in the 1920s situated the popularity of a certain structure of viewing experience in relation to the rise of a new class (the white collar worker). In contemporary terms, I would argue that the relevant transformation is the process of 'globalisation'. While this is a complex, heterogeneous and uneven phenomenon, a relevant aspect to consider here is Hollywood's increasing reliance on overseas markets, both for revenue, and, more importantly, for growth. ${ }^{41}$ In this context, the growing imperative for films to 'translate' easily to all corners and cultures of the world is answered by building films around spectacular action setpieces.

Equally as significantly, the predominant themes of recent special effects cinemathe destruction of the city and the mutation or dismemberment of the human body - are symptomatic of the underlying tensions of globalisation, tensions exemplified by widespread ambivalence towards the socio-political effects of speed and the new spatio-temporal matrices such as cyberspace. ${ }^{42}$ The most important cinematic manifestations of these anxious fascinations are not realised at the level of narrative 'content' (although they occasionally make themselves felt there), but appear symptomatically in the structure of contemporary viewing experience. The repetition of awe and astonishment repeatedly evoked by 'impossible' images as the currency of today's 'cutting edge' cinema undoubtedly functions to prepare us for the uncertain pleasures of living in a world we suspect we will soon no longer recognise: it is not simply 'realism' but 'reality' which is mutating in the era of digital economy and the Human Genome Project. If this turn to spectacle is, in some respects, comparable to the role played by early cinema in negotiating the new social spaces which emerged in the industrial city remade by factories and department stores, electrification and dynamic vehicles, it also underscores the fact that the 'death' of camera realism in the late twentieth century is a complex psycho-social process, not least because photo-realism was always less an aesthetic function than a deeply embedded social and political relation..$^{43}$ 
Finally, I would argue that it is important not to subsume all these filmic headings under the single rubric of 'digital'. There is a need to acknowledge, firstly, that digital technology is used far more widely in the film industry than for the production of blockbusters and special effects (for example, it is the new industry standard in areas such as sound production and picture editing). Moreover, as Elsaesser has argued recently, technology is not the driving force: 'In each case, digitisation is 'somewhere', but it is not what regulates the system, whose logic is commercial, entrepreneurial and capitalist-industrialist ${ }^{\prime 4}$ What the digital threshold has enabled is the realignment of cinema in conformity with new demands, such as 'blockbuster' marketing blitzes constructed around a few spectacular image sequences of the kind that propelled Independence Day to an US\$800m gross. It has rejuvenated cinema's capacity to set aesthetic agendas, and, at the same time, restored its status as a key player in contemporary political economy.

In this context, one aspect of the digital threshold deserves further attention. In the 1990s, product merchandising has become an increasingly important part of financing the globalised film industry. While some would date this from Star Wars, Jurassic Park offers a more relevant point of reference: for the first time, audiences could see on screen, as an integral part of the filmic diegesis, the same commodities they could purchase in the cinema foyer. As Lucie Fjeldstad (then head of IBM's multimedia division) remarked at the time (1993) : 'Digital content is a return-on-assets goldmine, because once you create Terminator 3, the character, it can be used in movies, in theme-park rides, videogames, books, educational products'. ${ }^{45}$ Digital convergence is enacted not simply in the journey from large screen to small screen: the same parameters used in designing CG characters for a film can easily be transmitted to off-shore factories manufacturing plastic toys. If digital technology has altered the boundaries of 'realism' in cinematic experience, this also corresponds to the increasing penetration of commodity culture into the interstices of film culture, and raises another possible future for the blockbuster narrative feature film - as a ninety minute ad for a new range of toys.

\section{(C) Scott McQuire 1999}

1 Thomas Elsaesser, 'The New Film History', Sight and Sound 55. no. 4 (1986), p. ?

${ }^{2}$ Global box-office takings have been growing rapidly for a decade, as have the number of cinema screens. Statistics in Australia illustrate the shift: while the number of theatres declined from 737 in 1983 to 567 in 1998, the number of screens nearly doubled from 863 to 1576 in the same period. Total seating capacity has barely risen (395 000 to 413000$)$, but the total number of 
admissions has more than doubled, rising from 37.1 million in 1983 to 80 million in 1998. All figures provided by the MPDAA [Motion Picture Distributors Association of Australia].

3 'The New Film History', p. 250.

${ }^{4}$ Sean Cubitt, 'Le réel, c' est l'impossible: the sublime time of special effects', Screen, 40, no. 2 (1999), p.123

5 'What is Digital Cinema?', http://jupiter.ucsd.edu/ manovich/text/digital-cinema.html (October 1999).

${ }^{6}$ Paul Young, 'The Negative Re-Invention of Cinema: Late Hollywood in the Early Digital Age', Convergence, 5, no. 2 (1999), p. 41. The reference is to Scott Bukatman's Terminal Identity: The Virtual Subject in Postmodern Science Fiction (Durham: Duke University Press, 1993), p. 14.

${ }^{7}$ Quoted in Warren Buckland, 'Between science fact and science fiction: Spielberg's digital dinosaurs, possible worlds and the new aesthetic realism', Screen, 40, no. 2, (1999), p.178. Buckland's concern is to partially refute such a view.

${ }^{8}$ The relevant percentages are 54 (1995), 59 (1996), 83 (1997) and 69 (1998). (Calculations made by the author based on the annual box-office surveys published by Variety). A similar picture is revealed if one looks at the global revenues of the 20 top-grossing films of all time: at least 13 are what I would call 'special-effects driven' films - Titanic (1), Jurassic Park (2), Star Wars Episode 1 The Phantom Menace (3),Independence Day (4), Star Wars (5), E.T (7), Lost World (9), Men in Black (10), Armageddon (11), The Empire Strikes Back (12), Terminator 2 (15), Indiana Jones and the Last Crusade (16), and Twister (17); 2 are animations The Lion King (6) and Aladdin (19), while the remaining titles are Forrest Gump (8), Home Alone (13), Ghost (14), Saving Private Ryan (18) and Jaws (20). Figures obtained from the Internet Movie Data Base

(www.uk.imdb.com/Charts/worldtopmovies/ November 11 1999). Clearly, such a list using unadjusted grosses is skewed in favour of recent releases: 2 are from the 1970s, 3 from the 1980s, 15 are from the 1990s.

${ }^{9}$ The Cinema of Attraction: Early Film, Its Spectator and the Avant-Garde', Wide Angle, 8, nos. 3-4 (1986), p. 70. The mere mention of Coppola in the same breath as Spielberg and Lucas dates the article as pre-digital and underlines its longevity.

10 'In the Realm of the Senses: Imax 3D and the Myth of Total Cinema', Film Comment, 32, no. 1 (1996), p. 79.

${ }^{11}$ Here I am drawing on research I have undertaken over the last 3 years, involving two projects commissioned by the Communications Law Centre and funded by the Australian Key Centre for Media and Cultural Policy and the Australian Film Commission; Crossing the Digital Threshold (1997)and Maximum Vision: Large Format and Special Venue Cinema (1999).

${ }^{12}$ See his 'The Architechsonic Object - Stereo Sound, Cinema and Colours' in Phil Hayward (ed.) Culture, Technology and Creativity at the End of the Twentieth Century (London, 1990), p. 91.

${ }^{13}$ Faden in Convergence 5, no. 2, (1999), pp. 51-79.

${ }_{14}$ All quotes from Ian McLoughlin taken from an interview with the author, April 1999.

${ }^{15}$ All quotes from Roger Savage taken from an interview with the author, May, 1997. Savage is ignoring the fact that 4-track stereo was an integral part of various wide-screen systems such as Cinerama, CinemaScope, TODD-AO introduced in the 1950s. However, in practice, the use of surround speakers was an exception rather than the rule, and variations from theatre to theatre were extreme, as George Lucas was to discover in the late 1970s. The motivation behind LucasFilm's development of the proprietary THX system was to better exploit multi-track recording by aligning sound mixing practices with speaker configuration in theatres.

${ }^{16}$ Rich Altman, 'The Sound of Sound: A Brief History of the Reproduction of Sound in Movie Theatres', Cineaste , 21, nos. 1-2, (1995) (on-line version:

http://www.geocities.com/Hollywood/Academy/4394/altman.html.)

${ }^{17}$ 'What is Digital Cinema?'

18 'Machines of the Visible' in Stephen Heath and Theresa de Lauretis (eds.), The Cinematic Apparatus (London, MacMillan, 1980), p. 130.

19 'True Lies: Perceptual Realism, Digital Images and Film Theory', Film Quarterly, 49, no. 3, (1996), p. 32 (emphasis added). 
${ }^{20}$ Quoted in Paula Parisi ‘Shot by an Outlaw' Wired 4.09 (1996). (on-line version: http://www.wired.com/wired/archive/4.09/)

${ }^{21}$ Quoted in Dominic Case, 'Flame at Complete Post' Cinema Papers 102 (1994), p. 63.

${ }^{22}$ Brad Fisher, 'Digital Cinematography: A Phrase of the Future? (Part 1), American

Cinematographer, 74, no. 4, (1993), p. 52.

${ }^{23}$ Michelle Pierson has characterised 'early' CGI (up to 1995) in terms of a distinctive hyper-real electronic aesthetic which is disjunctive to narrative flow. See her 'CGI Effects in Hollywood Science Fiction Cinema 1989-95', Screen, 40, no. 2, (1999), 158-176. In contrast, I am arguing that it is not so much the ambition for narrative 'integration' of CGI which has changed, but the capacity to realise that ambition.

${ }^{24}$ While the first Hollywood use of morphing was in Willow (1988), James Cameron has argued that Terminator 2 was the first film which made CGI pivotal to its outcome: '... on The Abyss the computer was really used to solve single sequences, and if that sequence had failed the film would still have succeeded dramatically. On T-2 the success or failure of the film was really predicated on the success or failure of the digital techniques'. Quoted in 'Cameron Angle', p. 133.

${ }^{25}$ Cameron quoted in Paula Parisi, 'The New Hollywood', Wired, 3.12 (1995). (on-line version: http://www.wired.com/wired/archive/3.12/)

${ }^{26}$ Muren quoted in Ron Magid, 'ILM's Digital Dinosaurs Tear Up Effects Jungle', American Cinematographer, 74, no. 12, (1993), p. 57; and in Ron Magid, 'CGI Spearheads Brave New World of Special Effects', American Cinematographer, 74, no. 12, (1993), p. 28.

${ }^{27}$ Quoted in Ron Magid, 'George Lucas: Past, Present and Future', American Cinematographer, 78, no. 2, (1997), p. 49.

28 'George Lucas: Past, Present and Future', p. 52.

${ }^{29}$ Scott Bukatman, 'The Artificial Infinite' in Lynne Cooke and Peter Wollen (eds), Visual Display: Culture Beyond Appearances (Seattle, Bay Press, 1995), pp. 254-289

30 'Visual pleasure in narrative cinema', Screen, 16, no. 3, (1975), p. 11. Bukatman is clearly aware of the connection of Mulvey's work to his own, but doesn't directly engage it.

${ }^{31}$ Cinema of Attraction, p. 68. Gunning cites George Méliès to emphasise the minor role that 'narrative' played in the 'cinema of attraction': 'As for the scenario, the "fable" or "tale", I only consider it at the end. I can state that the scenario constructed in this manner has no importance, since I use it merely as a pretext for the "stage effects", the "tricks", or for a nicely arranged tableau'. (p. 64)

${ }^{32}$ Gunning explicitly argues that the 'cinema of attraction' should not be conceived in terms of 'the opposition between narrative and non-narrative film making, at least as it is understood today'. (p.64) He also notes that the 'attraction' does not disappear with the turn to narrative in cinema around 1908, but goes 'underground' (p.64) and later refers to the 'primal power of the attraction running beneath the armature of narrative regulation'. (p. 70)

${ }^{33}$ Quoted in 'Cameron Angle', p. 179.

34 'If you have the sort of garage-band formula where you can sit there and don't care if it takes two days to render, it's going to reach a point pretty soon where you can do most of what can be done at a high-end facility. But that isn't really going to change the basic paradigm for film making. ... The thing that everybody fails to remember here is that when you're making a big effects film and you've got over 200 shots in the film, you've got issues of management, you've got issues of dealing with the day-to-day flow of the work, and you've got organizational problems. It's a little bit like saying, 'with these tools, I can go out in my backyard and build a car.' Well, yeah, you might be able to build a car, but can you build the Ford Motor Company? Can you build a thousand of them? I don't think so'. 'Cameron Angle', p. 178.

${ }^{35}$ Even makers of 'spectacular', immersive forms of cinema such as film 'rides' display similar concerns. Doug Trumbull, who produced the pioneering Back to the Future - The Ride, has stressed that 'narrative' is a critical element of successful ride films: 'There's dialogue, there's character development, suspense - all the normal cinematic elements. But it's not somebody else who is 
getting shot at, or catapulted out of a rocket. It's you. This is what I'm most interested in: the direct first person experience'. Cited in Escape from Gravity', Sight and Sound, (May 1995), p. 17. ${ }^{36}$ The Negative Re-Invention of Cinema', pp. 38, 41.

37 'Cinema of Attraction', p. 70. Gunning also explicitly cautioned against seeing the 'cinema of attraction' as an oppositional cinema. We should also recall that one of the principal qualities that he attributes to the 'exhibitionist' 'cinema of attraction' is the direct look at the camera, which became so heavily restricted in 'voyeuristic' classical narrative. While contemporary cinema is undoubtedly self-consciously reflexive in some areas, such as genre, it is still rare for films to deploy the mechanism of direct address, which has been largely annexed by television.

${ }^{38}$ See in particular his essay 'Cult of Distraction' in The Mass Ornament (Trans. T.Y. Levin), Cambridge MA, Harvard University Press, 1995, pp. 323-328. It should be noted that Kracauer argues distracted spectatorship assumes moral significance 'only if distraction is not an end in itself'. (p. 326)

${ }^{39}$ See Thomas Elsaesser, 'Cinema - The Irresponsible Signifier or "The Gamble with History": Film Theory or Cinema Theory', New German Critique 40 (1987), p. 86. For a further discussion of this issue, see my 'The Go-for-Broke Game of History', Arena no. 4 (1994/95), 201-227.

${ }^{40}$ See 'The Mass Ornament' in The Mass Ornament, pp. 75-86.

${ }^{41}$ Hollywood is now drawing more total revenue from global than domestic markets. Average spending on recreation and entertainment in the USA in 1997 was US\$1900 per annum, a figure which is projected to more than double to US $\$ 4900$ by 2007. ( Figures from Kagan's MediaCast 2007, reported in Business Wire, February 19, 1999.) While the media, entertainment and communications sector is forecast to grow faster than the rest of the economy, the highest growth is anticipated in new media, such as the Internet, while traditional film and publishing avenues will experience slightly less than average growth. In this context, international film revenues assume heightened importance for the US based multinationals which own the major Hollywood studios.

${ }^{42}$ I have discussed this issues at greater length in 'Pure Speed: From Transport to Teleport' in Jeremy Millar (ed.) Speed.: Visions of an Accelerated Age, (London, Photogrpahers Gallery, 1998). ${ }^{43}$ See my Visions of Modernity: Representation, Memory, Time and Space in the Age of the Camera, London, Sage, 1998.

44 'Digital Cinema: Delivery, Event, Time' in Thomas Elsaesser and Kay Hoffman (eds), Cinema Futures: Cain, Abel or Cable? (Amsterdam, Amsterdam University Press, 1998), p. 203.

${ }^{45}$ Quoted in Paula Parisi, 'The New Hollywood'. 


\section{University Library}

\section{- M M I N E R VA A gateway to Melbourne's research publications}

Minerva Access is the Institutional Repository of The University of Melbourne

Author/s:

MCQUIRE, SCOTT

Title:

Impact aesthetics: Back to the future in digital cinema?

Date:

2000

Citation:

McQuire, S. (2000). Impact aesthetics: back to the future in digital cinema? Convergence:

The journal of research into new media technologies, 6(2), 41-61.

Publication Status:

Published

Persistent Link:

http://hdl.handle.net/11343/34745 